\title{
Research on the Impact of Food Safety Crisis on Brand Trust: The Mediating Effect of Enterprise Information Transparency
}

\author{
Xu Zu ${ }^{1}{ }^{*}$, Weiping Yu ${ }^{2}$, Yue Qiu ${ }^{3}$ \\ ${ }^{1}$ Business School, Si Chuan Agricultural University, Chengdu, 611830; \\ ${ }^{2}$ Business School, Si Chuan University, Chengdu, 610065 \\ ${ }^{3}$ Graduate School, Chengdu University of TCM, Chengdu, 611137
}

Keywords: Food safety crisis; enterprise information transparency; brand trust

\begin{abstract}
This paper introduces enterprise information transparency to explore the negative impact of different types of food safety crisis on consumer brand trust. Studies have shown that: (1) Compared with negligence, deliberate food safety crisis often has a greater negative impact on consumer brand trust. (2) In the two types of food safety crisis, consumers' brand trust for low-information transparency enterprises is significantly lower than that of high-information transparency enterprises. (3) Enterprise information transparency has a regulating effect on good faith trust. Compared with the negligent food safety crisis, the goodwill trust of different enterprises in the deliberate food safety crisis is quite different. The conclusions of the study provide theoretical basis and practical reference for the follow-up crisis management strategy of food enterprises.
\end{abstract}

\section{Introduction}

In recent years, "Chinese tourists rushed to buy milk powder" and "Chinese tourists rushed to buy Japanese rice" and other similar news incidents have repeatedly exposed, indicating that consumers are not optimistic about the brand trust of China's agriculture-related food enterprises. The imperfect information disclosure mechanism makes the food market appear to be in violation of the ethics of business ethics. The "reverse selection" leads to market failure, which not only causes consumers to question the production capacity of food enterprises, but also reduces the goodwill of consumers to food enterprises. Trust.

Scholars' research focuses on the influencing factors of consumer trust, which is more common in personal factors and information factors. At the same time, existing research results are more scattered in consumers' trust in food safety, but the research results on the influencing factors of consumer brand trust are not yet More common. And brand trust is an important part of building a brand-consumer relationship, Willmott (2003) and Kitchin (2003) found that the formation of brand trust depends on the transparency of corporate information. In view of this, this paper introduces the degree of information transparency of enterprises to specifically explore the impact mechanism of different types of food safety crisis on consumer brand trust.

\section{Literature review and research hypothesis}

\subsection{Definition and classification of food safety crisis}

The food safety crisis is a negative exposure event, subordinate to the product injury crisis, with occasional and widely publicized attributes that have or may be dangerous to consumers, in order to clarify the food safety crisis of enterprises, The concept of the food safety crisis is further defined as: occasional foods that contain threats (or potential threats) to consumers' health toxic or hazardous substances, or nutritional problems such as substandard nutrition, have been widely exposed and concerned (or Possible) An event that has a huge negative impact on a business or society.

The classification criteria of the food safety crisis have not formed a unified conclusion. Based on the attribution theory perspective, they can be classified into three types: victim type, fault type 
and deliberate type. [This article excludes the almost irresponsible victim type from the perspective of attribution theory. Specifically, it explores the impact of the two types of food safety crises on consumer brand trust.

\subsection{Brand trust}

Yuan Denghua et al. (2007) design brand trust scale to divide brand trust into three dimensions: quality trust, ability trust and good faith trust. Quality trust is trust in brand quality, and ability trust is trust in brand ability to fulfill commitment. Good faith trust is the trust that the brand will further improve the product and solve the problem. This paper believes that the product quality is still reflected in the production capacity of the enterprise. Therefore, the integration of quality trust into a dimension of competence trust mainly uses brand competence and good faith trust. The criteria for the division of the two dimensions.

\subsection{Research hypothesis}

1) Analysis of the main effects of two types of food safety crisis

Since the deliberate food safety crisis involves business ethics, and the deliberate food safety crisis has a negative impact on the company's brand equity, trust can be transferred from the evidence source trusted by the credit card based on the transfer mechanism, and combined Lenovo theory, this study further speculates that compared with the negligent food safety crisis, the deliberate food safety crisis makes the consumer's good faith trust more negative, and based on the ripple effect, the deliberate food safety crisis makes the consumer's ability and trust more negative. The following assumptions are made:

H1: Deliberate food safety crisis has a negative impact on consumer brand (capability/goodwill) trust than negligent food safety crisis

\section{The adjustment of corporate information transparency}

Corporate information transparency is the relative degree to which market participants have easy access to all of the company's information. Chen (2008) pointed out that authenticity information is one of the main sources of consumer trust in food. Food companies can provide true information to avoid misunderstanding information and increase consumer trust. However, the availability of food safety information in the food market is low, the information dissemination channels are not smooth, and the quality and safety related information such as food production obtained by consumers is insufficient. Based on this, this study concludes that corporate information transparency can improve consumer brand trust level, and in different types of food safety crisis, high corporate information transparency can alleviate consumers' negative perception of crisis events and reduce corporate moral hazard. The following assumptions are made:

H2: In the food safety crisis, high corporate information transparency helps to counter the negative impact of brand (ability/goodwill) trust

Based on brand association theory, this study believes that high corporate information transparency increases consumer's association information source for corporate brand social responsibility image, and reduces consumers' negative responsibility for goodwill in food companies. In view of the negligent food safety crisis, the trust in good faith is negative. The impact is small, and the deterrent effect of the deliberate food safety crisis on the negative impact of good faith trust is more pronounced.

H3: Compared with the negligent food safety crisis, the degree of goodwill trust between different companies in the deliberate food safety crisis is greater

\section{Research design}

\subsection{Selected by the sample}

In this paper, college students are selected as experimental specimens for the following reasons: The first is to improve the homogeneity of the specimens and avoid the interference of the 
individual characteristics of the specimens on the experimental results. The second is that the campus population is highly sensitive and easy to accept new things, while college students with higher educational experience will become the backbone and guiding force of future market consumption.

\subsection{Stimulus design}

\subsubsection{Category, brand selection}

This article chooses juice beverage as a category of food safety crisis stimulants. At the same time, it uses the industry-represented Huiyuan juice as a prototype, combined with a number of network news reports on Huiyuan Juice to modify the stimulus materials of the company brand profile to control the juice beverage enterprise. Brand reputation, at the same time replace the Huiyuan juice brand name with the virtual A brand, eliminate the obvious feature information, eliminate the influence of existing consumer experience, and avoid the consumer's final interference with the experimental results due to the difference in corporate reputation perception.

\subsubsection{Experimental material design}

This article adds relevant stimulus materials for corporate information transparency after the company's brand profile, which is based on the patency of information channels, the principle of information availability and the status quo of information sharing results of the top ten brands of juice drinks, such as Huiyuan and Meijiyuan. High-level and low-level corporate information transparency stimulating materials.

Based on the Coca-Cola "chlorine-containing" incident in April 2012 and the "great fruit gate" incidents of the three major juice giants such as Huiyuan in September 2013, the news reports of several networks were combined and revised into two types: negligence and deliberate. The food safety crisis stimulates materials, and refers to the template of the crisis scandals by Xu Xiaolong and Su Yong (2015). The two types of crisis scandals have similar word counts (about 200 words).

\subsection{Variable measurement}

The measurement scales for psychological risk and brand trust (capability trust and good faith trust) are either used or modified in previous studies. The measurement of psychological risk is mainly based on the research of Stone \& Grønhaug (1993) and Founder et al. (2011). The measurement of competence and good faith trust in brand trust mainly refers to the brand trust scale of Yuan Shouhua et al. (2007) combined with Chinese scenario design.

The variables that are experimentally manipulated by the sample are brand reputation, corporate information transparency, and crisis severity. Ensure that the testees have similar evaluations of the company's brand reputation and avoid interfering with the experimental results. The brand reputation scale is designed with reference to the research of Chaudhuri (2002) and Li Guofeng (2008) and the product characteristics of the beverage industry. For the measurement of corporate information transparency, refer to the study by Hustvedt \& Kang (2013). Ensure that the subjects are similar in their perception of the severity of the two types of crisis events, refer to Coombs (1995) and Yan Jun, Qu Qiuling (2010) research scale. In addition, the crisis category consisted of two items: "fault type" and "deliberate type" of the food safety crisis.

The above variable measurement, except for the type of crisis belonging to the identification item, uses the 7-level Likert scale, and for the English scale item, the double-blind translation method is adopted to ensure the accuracy of the item.

\subsection{Experimental procedures}

This paper uses two stages of pretest and formal experiment. The experiments were conducted in three colleges and universities in Chengdu, and all the subjects were full-time undergraduate students.

In the pre-test phase, the paper is divided into two steps: First, 60 undergraduate students are invited as the sample, and the sample is distributed to the four experimental groups based on the 
random principle. Secondly, the participants were asked to explain the basic requirements of the questionnaire, and the participants were asked to carefully read the experimental materials held and responded according to the order of the questionnaires. In view of the fact that the experimental materials or items in the pre-test experiments are not easy to understand, this study invited two doctoral students and two master students in the research field to discuss each other and solve them.

The formal experimental phase is consistent with the specific implementation steps of the pre-test phase. In the formal experiment, the study randomly invited 240 full-time undergraduate students from three comprehensive universities in Chengdu to participate in the questionnaire survey. Each experimental group assigned 60 subjects to answer in accordance with the requirements of the experimental questionnaire.

\section{Data analysis}

\subsection{Sample overview}

A total of 240 experimental questionnaires were distributed in this experiment. After eliminating the sample questionnaires in which the crisis category was judged incorrectly, the answers were incomplete, or all the items were selected the same, the valid samples were finally determined, and the effective number of the participants in each experimental group was 45 . More than 89 people and 104 women. The subjects in this study were homogenous and the sample size met the experimental requirements. Based on analysis of variance, male and female genders had no significant effect on ability trust and good faith trust (F-capability trust $(1,191)=0.021$, $\mathrm{p}=0.885>0.05$; F-good faith trust $(1,191)=0.014, \mathrm{p}=0.907>0.05)$.

\subsection{Reliability and validity test}

All variables are based on the maturity scale, so the reliability and validity are good. First, in the reliability test, the alpha coefficient of corporate information transparency is 0.926, the alpha coefficient of psychological risk is 0.948, the alpha coefficient of competence trust and good faith trust is $0.957,0.948$, respectively, and the alpha coefficient of brand reputation and crisis severity is 0.906. , 0.939. Secondly, the results of confirmatory factor analysis show that the minimum value of the normalized factor load factor of the measurement items of each variable is 0.796 , and the maximum value is 0.893 , which is between 0.5 and 0.95 . The internal structure is well fitted and the average of each variable is average. The extracted variance AVE values ranged from 0.67 to 0.87 , both greater than the critical criterion of 0.5 .

\subsection{Control inspection}

This experiment successfully manipulated brand reputation, crisis severity and corporate information transparency. The results of variance analysis showed that there was no significant difference in brand reputation among the experimental groups $(\mathrm{Mmin}=5.430, \mathrm{M} \max =5.776, \mathrm{~F}(3$, $189)=1.653, p=0.179$ ), and the experiment of high-level enterprise information transparency There was a significant difference between the experimental group and the low-level enterprise information transparency $(\mathrm{M}$ high transparency $=5.297, \mathrm{M}$ low transparency $=3.328, \mathrm{~F}(1,191)=$ $178.353, \mathrm{p}=0.000<0.05$ ), and the trial group was severely affected by the crisis. There was no significant difference in the degree of sensuality $(\mathrm{Mmin}=5.250, \mathrm{Mmax}=5.521, \mathrm{~F}(3,189)=0.450$, $\mathrm{p}=0.717)$.

\subsection{Hypothesis testing}

In this paper, with the capability trust and good faith trust as the dependent variables, the two-factor analysis of variance (H1) and the transparency of corporate information transparency (H2 and H3) were verified by two-way analysis of variance.

First verify H1. Two-way analysis of variance showed that the negative impact of the negligent food safety crisis and the deliberate food safety crisis on capacity trust was significant $(F(1,191)=9.833, p=0.002) . H 1$ is verified.

Secondly verify H2. Through two-way analysis of variance, it is concluded that the negative 
impact of food safety crisis on capacity trust under different enterprise information transparency is significant $(\mathrm{F}(1,191)=48.503, \mathrm{p}=0.000)$, among which the consumer is low in the negligent food safety crisis. Capability trust under corporate information transparency is significantly lower than capacity trust under high corporate information transparency $(\mathrm{M}$ high transparency $/$ fault type $=$ 4.83, SD high transparency / fault type $=0.949$; M low transparency / fault type $=3.695$, SD low transparency / Negligent type $=0.945$ ), in the deliberate food safety crisis, consumers' ability to trust in low corporate information transparency is significantly lower than that of high corporate information transparency $(\mathrm{M}$ high transparency / deliberate type $=4.344$, SD high transparency / deliberate type $=1.477$; $\mathrm{M}$ low transparency / deliberate type $=3.172$, SD low transparency / deliberate type $=1.193$ ); food security crisis under different corporate information transparency has a significant difference in the negative impact of good faith trust $(F(1,191)=56.028, p=0.000$ In the case of a negligent food safety crisis, consumers' trust in good faith in low corporate information transparency is significantly lower than that in high corporate information transparency (M Transparency / Negligence $=4.907$, SD High Transparency / Negligence $=1.031 ; \mathrm{M}$ Low Transparency / Negligence $=4.022$, SD Low Transparency / Negligence $=0.948$ ), Deliberate Food Safety Crisis, Consumers Under Low Corporate Information Transparency Good faith trust is significantly lower than good faith trust in high corporate information transparency ( $\mathrm{M}$ high transparency / deliberate type $=4.224$, SD high transparency / deliberate type $=1.427$; M low transparency / deliberate type $=2.632$, SD low transparency / deliberate type $=1.079$ ). H2 was verified.

Finally verify H3. Still relying on competency trust and good faith as dependent variables, two-way ANOVA is used to verify the interaction between food safety crisis categories and corporate information transparency on competency trust (or good faith trust). The results of variance analysis show (Figure 2): Negligent type In the food safety crisis and the deliberate food safety crisis, there is no significant difference in the degree of consumer trust in the transparency of information transparency among different companies $(F(1,191)=0.002, p=0.963>0.05)$; and the food safety crisis with negligence In contrast, the good faith trust of different corporate information transparency in the deliberate food safety crisis is quite different $(F(1,191)=4.556, p=0.34<0.05)$. H3 was verified.

\section{Conclusions and implications}

\subsection{Research conclusions}

This paper verifies the negative impact of the food safety crisis on consumer brand trust through empirical research, as well as the regulatory role of corporate information transparency, and draws the following specific research conclusions:

First, in contrast to the negligent food safety crisis, deliberate food safety crises often have a greater negative impact on consumer brand trust. After the deliberate food safety crisis, consumers have lower confidence in the ability and good faith of food companies, thus verifying that consumers attach great importance to the business ethics of food companies.

Second, in the two types of food safety crisis, consumers' brand trust in low-information transparency companies is significantly lower than that of high-information transparency companies. After the deliberate food safety crisis and the negligent food safety crisis, consumers will have lower capacity trust and good faith trust for food companies with low information transparency.

Third, corporate information transparency has a regulatory effect on consumer trust in good faith. In the two types of food safety crises: negligence and deliberate type, there is no significant difference in the degree of consumer trust in the transparency of information transparency among different companies. Compared with the negligent food safety crisis, the goodwill of information transparency in different companies in the deliberate food safety crisis The difference in trust is greater. 


\subsection{Management enlightenment}

First, build a mobile Internet enterprise information sharing platform to carry out quality monitoring and information transparency. Through comprehensive monitoring, it can improve food safety and quality, prevent food safety problems, and also facilitate product innovation and information dissemination, enhance corporate information transparency, and effectively counter the negative brand effect of food safety crisis.

Second, through the interaction of social media, strengthen the communication of quality and emotional information. Consumers understand the relevant information of food companies to avoid the crisis of information channels, improve the transparency of information in food companies, and thus enhance the trust of consumers in good faith.

Third, consider the ethical and performance factors and deal with the food safety crisis. In the event of a negligent food safety crisis, food companies should actively transmit high-quality signals from enterprises. When a deliberate food safety crisis occurs, food companies should focus on delivering honest and trustworthy business ethics signals to consumers.

\section{Acknowledgements}

Fund Project: Key Research Base of Philosophy and Social Science of Sichuan Province--Southwestern Poverty Reduction and Development Research Center Key Project (SCP1802); Sichuan Agricultural University Social Science Key Project (2018ZD04); Sichuan Province Philosophy and Social Science Key Research Base--Sichuan Agriculture Featured Brand Development and Communication Research Center General Project (CAB1810)

\section{References}

[1] Hustvedt G, Kang J. Consumer Perceptions of Transparency: A Scale Development and Validation [J]. Family \& Consumer Sciences Research Journal, 2013, 41(3): 299-313.

[2] Willmott M. Citizen brands: Corporate citizenship, trust and branding [J]. Journal of Brand Management, 2003, 10(4-5): 362-369.

[3] Kitchin T. Corporate social responsibility: A brand explanation[J]. Journal of Brand Management, 2003, 10(4): 312-326.

[4] Siomkos G J, Kurzbard G. The Hidden Crisis in Product-harm Crisis Management [J]. European Journal of Marketing, 1994, 28(2): 30-41

[5] Fang Zheng, Yang Yang, Li Wei, et al. Study on the occurrence conditions and coping strategies of product injury crisis spillovers_—Predicting and responding to product injury crisis caused by other brands[J]. Nankai Management Notes, 2013, 16(6) :19-27.

[6] Coombs W T. Protecting Organization Reputations During a Crisis: The Development and Application of Situational Crisis Communication Theory [J]. Corporate Reputation Review, 2007, 10(3): 163-176.

[7] Yuan Denghua, Luo Yuming, Li You. Research on Brand Trust Structure and Its Measurement[J]. Psychology, 2007, 27(3): 81-86.

[8] Duan Guimin, Yu Weiping. Research on the Impact of Sub-brand Injury Crisis on the Evaluation of Main Brands__-Intermediary Role of Consumer Negative Emotions[J]. East China Economic Management, 2012, 26(4): 115-119.

[9] Zhang Chengrui, Wang Hua. Corporate Information Transparency: Empirical Research and Future Prospects [J]. Accounting Research, 2006(12): 54-60.

[10]Chen M F. Consumer trust in food safety--a multidisciplinary approach and empirical evidence from Taiwan. [J]. Risk Analysis, 2008, 28(6): 1553-1569. 
[11]Quan Shiwen, Zeng Yichu. Consumers' Search Behavior on Food Safety Information_-Based on the Survey of Consumers in Beijing[J]. Agricultural Technology \& Economy, 2013(4): 43-52.

[12]Xu Xiaolong, Su Yong. Consumer-Brand Relationship Renewed under Product Injury Crisis__An Input Model Perspective[J]. Economic Management, 2015(5): 85-96. 